\section{EDUCAÇÃO EMPREENDEDORA: O QUE DIZEM OS ARTIGOS MAIS RELEVANTES? PROPOSIÇÃO DE UMA REVISÃO DE LITERATURA E PANORAMA DE PESQUISA}

\author{
Artur Tavares Vilas Boas Ribeiro' \\ Guilherme Ary Plonski²
}

\section{RESUMO}

Objetivo do estudo: o presente artigo tem como objetivo analisar o panorama da literatura acadêmica em ensino de empreendedorismo, identificando tópicos de concentração e tendências para estudos futuros.

Metodologia: este trabalho adotou como método a Revisão Sistemática de Literatura, implementando um algoritmo de ranqueamento para organização de relevância de uma amostra de 934 trabalhos sobre ensino de empreendedorismo.

Principais resultados: com o algoritmo, foram identificados 54 artigos correspondentes a $50 \%$ do volume total de citações médias acumuladas em toda a amostra, o que permitiu uma análise de conteúdo e organização de tópicos e tendências. Foram identificados 9 grupos principais, com grande concentração de trabalhos no tópico "intenção empreendedora". Três horizontes de pesquisa ainda a serem explorados emergiram da análise: a) ensino de empreendedorismo e novas abordagens em sala de aula; b) a ótica de ecossistemas de empreendedorismo no ensino e estudantes como atores no processo de formação; c) temas emergentes, como cultura, gênero e negócios sociais.

Contribuições teóricas/metodológicas: o trabalho contribui em apresentar um método diferenciado para definição de relevância de artigos em estudos bibliométricos, método este não encontrado nas revisões anteriores sobre ensino de empreendedorismo. Além disso, dos resultados emergiram provocações para estudos robustos, tais como estudos qualitativos que permitam a identificação de variáveis moderadoras relevantes para o tema.

Relevância/originalidade: além do diferencial metodológico, esta pesquisa mostra-se original pela organização dos diversos trabalhos em ensino de empreendedorismo, podendo ser um material de consulta sobre referências fundamentais para diferentes pesquisadores no tema em começo de jornada.

Palavras-chave: Educação Empreendedora; Ensino de Empreendedorismo; Revisão Sistemática de Literatura; Estudos Bibliométricos; Empreendedorismo.

Received on: 03/06/2019 / Approved on: 02/08/2019

Responsible editor: Profa. Dra. Vânia Maria Nassif

Doi: http://dx.doi.org/10.14211/regepe.v9i1.1633

\footnotetext{
${ }^{1}$ Faculdade de Economia, Administração e Contabilidade - FEAC/USP, São Paulo (Brasil). E-mail: artur.tavr@gmail.com Orcid id: https://orcid.org/0000-0002-0951-7191

${ }^{2}$ Faculdade de Economia, Administração e Contabilidade - FEAC/USP, São Paulo (Brasil). E-mail:plonski2@usp.br Orcid id: https://orcid.org/0000-0002-8949-4363
} 


\section{ENTREPRENEURSHIP EDUCATION: WHAT DO THE MOST RELEVANT PAPERS SAY? LITERATURE REVIEW AND RESEARCH AGENDA}

Aim of the study: this article aims to analyze the current literature in entrepreneurship education, identifying main topics and trends for future studies.

Methodology: this study adopted a Systematic Literature Review methodology, implementing a ranking algorithm to organize the relevance of a sample of 934 studies on entrepreneurship education.

Main results: with the algorithm, 54 articles corresponding to $50 \%$ of the total volume of cumulative mean citations were identified in the whole sample, which allowed contents analysis and an organization of topics and trends. Nine main groups were identified, with a great concentration of works on the topic "entrepreneurial intention". Three research horizons to be explored emerged from the analysis: a) entrepreneurship education and new approaches within the classroom; b) the perspective of entrepreneurship ecosystems in education and students as actors in the educational process; c) emerging issues such as culture, gender and social affairs.

Theoretical / methodological contributions: the work contributes by presenting a differentiated method to define the relevance of articles in bibliometric studies, a method not found in previous reviews on entrepreneurship education. In addition, the results emerged as thought provoking for robust studies, such as qualitative studies that allow the identification of relevant moderators.

Relevance / originality: besides the methodological differential, the work shows itself original by the organization of the various works in entrepreneurship teaching, being able to be a reference guide about fundamental works for different researchers in the subject at the beginning of their work.

Keywords: Entrepreneurship Teaching; Entrepreneurship Education; Systematic Review of Literature; Bibliometric Studies; Entrepreneurship. 


\section{EDUCACIÓN EMPRENDEDORA: ¿QUÉ DICEN LOS ARTÍCULOS MÁS RELEVANTES? PROPUESTA DE UNA REVISIÓN DE LA LITERATURA Y UNA VISIÓN GENERAL DE LA INVESTIGACIÓN}

Objetivo del estudio: este artículo tiene como objetivo analizar el panorama de la literatura académica sobre educación emprendedora, identificando temas de concentración y tendencias para futuros estudios.

Metodología: este trabajo adoptó la revisión sistemática de la literatura como método, implementando un algoritmo de clasificación para la organización de relevancia de una muestra de 934 trabajos sobre educación emprendedora.

Resultados principales: Con el algoritmo, se identificaron 54 artículos correspondientes al $50 \%$ del volumen total de citas promedio acumuladas a lo largo de la muestra, lo que permitió un análisis de contenido y la organización de temas y tendencias. Se identificaron nueve grupos principales, con una gran concentración de trabajos sobre el tema "intención emprendedora". Del análisis surgieron tres horizontes de investigación aún por explorar: (i) enseñanza del emprendimiento y nuevos enfoques en el aula; (ii) la perspectiva de los ecosistemas de emprendimiento en educación y estudiantes como actores en el proceso de formación; (iii) temas emergentes como cultura, género y negocios sociales.

Contribuciones teóricas/metodológicas: el artículo contribuye a presentar un método diferente para definir la relevancia de los artículos en estudios bibliométricos, un método que no se encontró en revisiones anteriores sobre educación en emprendimiento. Además, de los resultados surgieron provocaciones para estudios sólidos, como los estudios cualitativos que permiten la identificación de variables moderadoras relevantes para el tema.

Relevancia / originalidad: además del diferencial metodológico, el trabajo es original por la organización de los diversos trabajos en educación emprendedora, y puede ser un material de consulta sobre referencias fundamentales para diferentes investigadores sobre el tema en sus primeras etapas.

Palabras clave: Educación Emprendedora; Enseñanza de Emprendimiento; Revisión Sistemática de la Literatura; Estudios Bibliométricos; Emprendimiento. 


\section{INTRODUÇÃO}

Há mais de uma década, Kuratko (2005) chamava a atenção para a legitimidade acadêmica alcançada pela educação empreendedora (entrepreneurship education). Esse tópico ainda fomenta pesquisas, por exemplo, acerca das melhores formas de se estimular o empreendedorismo em ambientes de ensino (Nabi, Liñán, Fayolle, Krueger, \& Walmsley, 2017; Fayolle, \& Gailly, 2015).

Em paralelo ao trabalho de Kuratko, que destacava os mecanismos formais dos agentes de ensino no suporte ao empreendedorismo entre estudantes do ensino superior, Politis (2005) publicava um artigo defendendo que "tentativas de estimular uma atividade empreendedora por meio de treinamento formal e educação provavelmente não apresentam qualquer impacto relevante $e$ direto no desenvolvimento de conhecimento em empreendedorismo" (p. 417, tradução nossa).

Da contradição de visões nascia dos objetivos diferentes dos estudos. Enquanto Kuratko buscou apresentar horizontes possíveis, adotando um tom mais otimista em sua narrativa, Politis buscava analisar de maneira criteriosa a formação de empreendedores no ensino superior, defendendo que tal processo ocorre durante uma vida toda, sendo responsabilidade das universidades formar competências transversais, como criatividade, pensamento crítico e autorreflexão.

Do debate, emergem questões, tais como: houve evolução na literatura sobre ensino de empreendedorismo e seus horizontes para além da abordagem formal? Quais as novas fronteiras consideradas nesse debate?

Maritz e Brown (2013) reforçam que, dada a multiplicidade de abordagens, audiência, objetivos e tantos outros fatores, o tema passa a se enfraquecer devido à superficialidade de resultados produzidos e à falta de sistematização de conceitos. A organização dos trabalhos, com esforços de categorização e estruturação conceitual, passa a ser fundamental. No Brasil, por exemplo, até mesmo a tradução do termo "entrepreneurship education" é de difícil tratamento, sendo a forma mais comum, "educação empreendedora", criticada por utilizar um adjetivo para incitar finalidade. No caso, a forma adequada seria "educação para o empreendedorismo", utilizando-se de uma locução adverbial de finalidade.

Em um esforço organizador, Neck e Greene (2011) classificam quatro escolas na literatura sobre ensino de empreendedorismo: a) centrada no comportamento individual do empreendedor e na discussão sobre perfis; b) centrada no processo de criação e na natureza das empresas, estimulando o entendimento 
de exercícios de planejamento; c) centrada no processo cognitivo e na intenção/decisão, atentando-se ao desenvolvimento de modelos mentais; e d) centrada no método e na ação eficaz, desenvolvendo-se por meio de experiências concretas. Com atenção à ação, incorporam-se os debates sobre experiential learning em empreendedorismo (Corbett, 2005) e action-based entrepreneurship training (Gielnik, Frese, Kahara-Kawuki, Wasswa Katono, Kyejjusa, Ngoma, \& Oyugi, 2015; Frese, 2009).

Nessa evolução, o balanço da literatura sobre ensino de empreendedorismo no Ensino Superior ainda pende para abordagens em sala de aula, provocando a necessidade de reflexões sobre agendas futuras. Como reforçam Rae, Gee e Moon (2010): aprender sobre empreendedorismo é um ato social, orientado à prática/experiência que envolve crescimento pessoal, não seguindo o modelo tradicional expositivo com caminhos pré-estabelecidos, devendo ser estimulante, interessante, prazeroso e relevante para o contexto do aprendiz.

Nessa linha de pensamento, surgem trabalhos recentes provocando a necessidade de uma nova abordagem para a análise da formação de universitários em torno do tema "empreendedorismo": a visão que considera a formação enraizada no ecossistema da universidade, abrangendo não somente as salas de aula, mas também atividades extracurriculares, como grupos de competição, atividades esportivas e outras atividades criadas e gerenciadas pelos próprios alunos, sendo estes, atores centrais do fenômeno (Padilla-Angulo, 2019; Ribeiro, Zancul, AxelBerg, \& Plonski, 2018; Preedy \& Jones, 2015; Etzkowitz, 2013).

Desta forma, o presente trabalho analisa o panorama da literatura acadêmica em "educação para o empreendedorismo" e debate tendências futuras de modo a orientar educadores, administradores e pesquisadores a refletirem acerca de suas práticas e abordagens. O artigo segue da seguinte maneira: a seção dois trata do referencial teórico, com ênfase nas principais revisões de literaturas produzidas em ensino de empreendedorismo; a seção três apresenta o aspecto metodológico do estudo; a seção quatro apresenta os resultados do método; a seção cinco explora as discussões sobre os resultados encontrados; e a seção seis traz a conclusão do estudo, com suas limitações e horizontes futuros. 


\section{A CONSTRUÇÃO DA LITERATURA EM ENSINO DE EMPREENDEDORISMO POR MEIO DE SUAS PRINCIPAIS REVISÕES SISTEMÁTICAS}

Nas revisões de literaturas e estudos bibliométricos bem posicionados na produção acadêmica relativa ao tópico "ensino de empreendedorismo" encontram-se artigos considerados clássicos, como o "The chronology and intellectual trajectory of American entrepreneurship education 1876-1999" (Katz, 2003), e outros recentes, como o reconhecido trabalho de Nabi et al. (2017). Este último analisa o impacto do ensino de empreendedorismo no ensino superior e seu panorama de desenvolvimento futuros.

Neste presente estudo, construído a partir das principais revisões sistemáticas presentes no ranking de artigos publicados no assunto (a ser descrito na próxima seção), encontraram-se três principais agrupamentos temáticos: 1) a fase das apreciações (assessments) sobre o cenário nascente do assunto na academia; 2) a fase da proposição de arcabouços conceituais (frameworks); e 3) a fase de metanálises. As três fases, embora não perfeitamente, aparentam possuir uma temporalidade em comum, o que é esperado do desenvolvimento das escolas de pensamento na literatura acadêmica.

\subsection{Fase 1: Período de Apreciações sobre o Cenário do Ensino de Empreendedorismo.}

As primeiras grandes análises voltaram-se à avaliação do cenário de ensino de empreendedorismo. Katz (2003), por exemplo, em seu seminal artigo, apresentava em detalhes a construção do ensino de empreendedorismo como disciplina científica nos Estados Unidos, como a história do primeiro curso, oferecido em 1947 por Myles Mace em um programa de MBA na Harvard Business School, bem como a evolução temporal das publicações e a criação de periódicos específicos.

Kuratko (2005), analisando a emergência do assunto, seus desafios e oportunidades, chegava à mesma conclusão que Katz: o tema encontrava-se em relativa maturidade devido à consistência de publicações, autores e periódicos. Adotando um tom mais provocativo que seu antecessor, Kuratko apresentava dez grandes desafios para os acadêmicos: 1) evitar a armadilha da maturidade, Rev. Empreendedorismo Gest. Pequenas Empres. | São Paulo, v.9 | n.1 | p. 10-41 | Janeiro. 2020. 
provocando a necessidade de formar novos docentes; 2) estabelecer-se em periódicos de relevância; 3) criar programas específicos em empreendedorismo, inclusive no nível de doutoramento; 4) absorver práticas modernas baseadas em tecnologia, como ensino a distância; 5) orientar-se à formação de empreendedores com visões ousadas em termos de impacto, não somente focadas em retorno financeiro e de curto prazo; 6) aproximar acadêmicos e empreendedores para a construção dos currículos; 7) evitar tornar-se um tópico genérico e superficial, dado seu estabelecimento como "assunto da moda"; 8) compreender que docentes precisam assumir riscos para vivenciar o empreendedorismo, embora isso contrarie a ideia de segurança da vida acadêmica; 9) apontar a consistência por parte de administradores, garantindo manutenção de políticas e programas de empreendedorismo nas universidades; 10) engajar os indivíduos que fazem avançar o trabalho do ensino de empreendedorismo nas universidades: os professores e professoras.

\subsection{Fase 2: Emergência das Propostas para um Arcabouço Agregador}

Os trabalhos de Katz e Kuratko podem ser considerados como os que trouxeram uma primeira apreciação criteriosa sobre o panorama da comunidade científica em torno do tema "ensino de empreendedorismo". Após esse período, temse uma transição para estudos bibliométricos, que buscaram maior categorização para a construção de arcabouços que orientassem acadêmicos e gestores do ensino superior no desenho de seus esforços. Surgiam assim, diversos trabalhos cuja proposta era a proposição e análise de arcabouços analíticos (analytical frameworks) (Béchard, \& Gregoire, 2005; Pittaway, \& Cope, 2007; Fayolle, 2013).

Para Béchard e Gregoire (2005), a importância dos frameworks se dá devido ao fato de vários deles chamarem atenção para tópicos negligenciados na literatura, o que os autores tratam como "research preoccupations". Em seus argumentos, destacam como trabalhos clássicos foram "abre-alas" no desenvolvimento de linhas de pesquisa em ensino do empreendedorismo, graças às preocupações de pesquisa por eles levantadas. Alguns casos emblemáticos indicados são: Vesper (1982), convidando acadêmicos a produzirem trabalhos quantitativos com atenção específica a elementos dos programas de ensino de empreendedorismo, e Young 
(2000), trazendo maior ênfase a aspectos cognitivos da formação de empreendedores, como modelos mentais e memória.

No arcabouço de Béchard e Gregoire (2015), construído a partir de uma revisão de literatura, cuja análise de conteúdo se concentrou em estudar os resumos (abstracts), objetivos das pesquisas e conclusões, as abordagens educacionais sobre o ensino de empreendedorismo podem se dividirem em quatro grandes grupos baseado no foco: no conteúdo, nas interações, no indivíduo e na interface com a sociedade.

Já Pittaway e Cope (2007) apresentam uma abordagem sistêmica, com uma ótica orientada ao ambiente da universidade, produzindo uma organização das temáticas tratadas em artigos acadêmicos sobre ensino de empreendedorismo publicados entre 1970-2004. A revisão sistemática, que é um dos trabalhos mais citados sobre ensino de empreendedorismo, destaca-se pela análise de conteúdo orientada à codificação de temas por meio de contagem de caracteres, gerando um arcabouço abrangente.

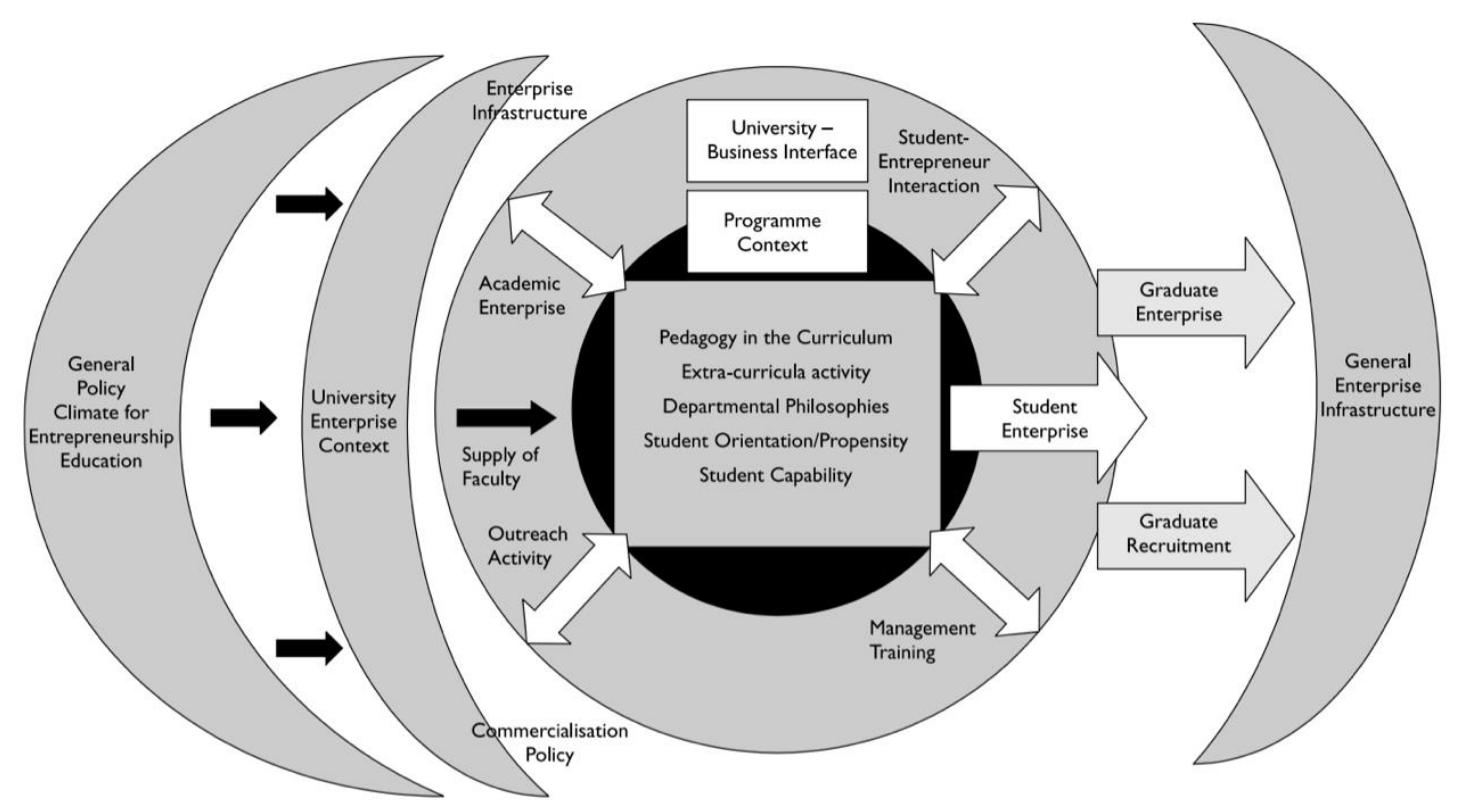

Figura 1: Um framework temático para Ensino de Empreendedorismo Autores: Pittaway e Cope (2007)

Por fim, um terceiro arcabouço relevante para a literatura encontra-se no trabalho "Personal views on the future of entrepreneurship education" de Fayolle (2013). Embora o texto constitua um ensaio crítico, não utilizando método sistemático de revisão de literatura, o autor deixa claro que suas observações são resultado de três revisões por ele realizadas. 
Em oposição ao trabalho de Pittaway e Cope (2007), cujo foco era um arcabouço abrangente sobre todo o ambiente universitário, Fayolle (2013) propôs um modelo voltado para as atividades de ensino de empreendedorismo dividido em dois níveis: o didático e o filosófico. No nível filosófico, o seu modelo provoca os professores a se questionarem sobre: a) o "porquê" da atividade, com objetivos e metas; b) "para quem", com público-alvo definido; c) "como", com métodos e abordagens pedagógicas; d) "o quê", com conteúdos específicos; e) "para quais resultados", com um sistema de avaliação do curso bem delineado. No nível filosófico, as questões versam sobre o significado do ensino de empreendedorismo, o significado da educação para o contexto do empreendedorismo e os papéis de educadores e participantes nesse processo.

\subsection{Fase 3: Período das Metanálises}

$\mathrm{Na}$ literatura recente, surgiu um maior número de trabalhos cuja proposta principal era a análise do que estava sendo produzido academicamente. Entende-se que essa movimentação vem como fruto do amadurecimento da produção acadêmica em ensino de empreendedorismo, permitindo uma reflexão criteriosa sobre métodos empregados e validade dos resultados.

Martin, McNally e Kay (2013), por exemplo, destacam na metanálise algumas contradições nos resultados: alguns trabalhos apontam uma associação positiva do ensino e treinamento em empreendedorismo com a criação de uma empresa, ao passo que outros encontravam associação negativa. Em uma análise criteriosa de 42 amostras diferentes $(\mathrm{N}=16.657)$, os autores concluíram que a literatura em ensino e treinamento de empreendedorismo ainda carece de estudos de melhor qualidade, pois das 42 amostras analisadas, 31 não atingiam um rigor metodológico de alto padrão (como o uso de pré e pós testes, além de grupos de tratamento e controle para minimização de vieses).

Similar ao trabalho dos autores acima, Rideout e Gray (2013) apresentaram uma revisão utilizando o modelo de Storey (2000) para avaliarem os trabalhos em ensino de empreendedorismo. O modelo divide a qualidade metodológica de um trabalho em 6 passos, agrupados em dois grandes grupos: os passos 1 a 3 caracterizam-se pela natureza de monitoramento, na qual a ênfase é oferecer apenas descrições por parte dos envolvidos, sendo os dados ligados a atitudes, 
opiniões e percepções, permitindo pouca sustentação para qualquer inferência criteriosa. Já os passos 4 a 6 tornam-se progressivamente robustos em termos metodológicos, trabalhando com grupos de controle e outros tratamentos sofisticados.

Após levantar os estudos sobre ensino de empreendedorismo nas universidades, produzidos entre os anos de 1997 e 2011, apenas 12 estudos apresentaram um nível de sofisticação robusto (passo 4 ou superior). Segundo os autores, o fenômeno ocorre pela sua natureza: "o ensino de empreendedorismo parece ser um destes fenômenos nos quais a ação e a intervenção correram muito à frente do estabelecimento da teoria, da pedagogia e da pesquisa acadêmica necessária para justificá-los e explicá-los” (Rideout, \& Gray, 2013, p. 346, tradução nossa).

Como horizontes para trabalhos futuros, os autores defendem a necessidade de: a) caminhar em direção a pesquisas com maior poder de inferência; b) utilizar mais estudos baseados em quasi-experimentos; c) buscar robustez em estudos experimentais poderosos; e d) produzir estudos de caso bem elaborados de modo a identificar potenciais elementos mediadores e afins.

Finalmente, tem-se o trabalho de Nabi et al. (2017), que reforça o conceito da ciência como uma construção sobre ombros de gigantes: a sua revisão de literatura concentrou-se em analisar 159 trabalhos publicados no período de 20042016, estando baseada nos arcabouços propostos por Béchard e Grégorie (2005), Fayolle e Gailly (2008) e Jack e Anderson (2002). Alguns desses autores estão presentes em tópicos anteriores da presente revisão, corroborando com a ideia de uma construção conceitual da literatura baseada em ondas temporais de esforços específicos. Nabi et al. (2017) destacam a necessidade de aprofundamento, com provocações importantes:

- Dado que empreendedorismo depende de disposições individuais à tomada de ação, é preciso desenvolver melhores indicadores relativos a questões emocionais e ligadas à mentalidade na formação de alunos;

- Há um elevado número de trabalhos baseados em intenção de empreender, mas faz-se necessária a produção de trabalhos que analisem a transição de intenção para o ato de empreender em si (intention-to-behavior transition); 
- Existem contradições de resultados sobre o impacto de atividades de ensino de empreendedorismo, portanto, é preciso aprofundar nos contextos que levaram a isso (tipo de curso, tipo de instituição, gênero, cultura local, etc.);

- Abordagens pedagógicas diferentes podem gerar resultados diferentes, sendo necessária a realização de estudos discriminantes que permitam comparações e inferências sobre a efetividade delas.

Os autores também mencionam a questão do ensino de empreendedorismo por meio de programas baseados em experiências, assim como a vivência em grupos liderados por estudantes no estímulo ao empreendedorismo. Essa constatação remete à introdução do presente trabalho com a seguinte questão de pesquisa: tem a literatura acadêmica acompanhando as novas abordagens no ensino de empreendedorismo, especificamente produzindo conhecimento relevante para contextos fora do modelo tradicional de sala de aula?

\section{INSTRUMENTOS E MÉTODOS}

Para o presente trabalho, foi empregado o método de Revisão Sistemática de Literatura, sendo a análise dos dados baseada em análise de conteúdo. Buscando responder à questão acima, o método empregado tem como objetivo analisar o panorama da literatura acadêmica em ensino de empreendedorismo, debatendo sobre tendências futuras de modo a orientar educadores, administradores e pesquisadores a refletirem acerca de suas práticas e abordagens. Com esse objetivo em mente, cabe destacar que a pesquisa não se concentrou em analisar os principais autores, as relações de co-citação e os principais periódicos, mas sim procedimentos comuns em estudos bibliométricos que fogem ao foco de identificação do panorama atual da literatura e tendências futuras de pesquisa.

Os procedimentos utilizados seguiram as seis etapas de Cooper (2009): 1) definição dos tópicos para busca bibliométrica e organização do algoritmo de busca; 2) realização da busca e limpeza inicial da primeira base de dados resultante; 3) estruturação da base de dados; 4) tratamento da base de dados para geração de um ranking de relevância acadêmica; 5) categorização dos principais trabalhos; e 6) análise do conteúdo. 
De modo a garantir abrangência, a definição dos tópicos para a busca bibliométrica envolveu os seguintes termos: "entrepreneurship education"; "entrepreneurship training"; "entrepreneurial learning"; "enterprise education". algoritmo de busca baseou-se no operador booleano "OR", de modo a capturar diferentes usos independentes das expressões. A busca foi executada na plataforma Web of Science, considerada uma boa opção por incluir outras bases de dados acadêmicas (Scopus, ProQuest e Wiley) e fornecer metadados relevantes para o tratamento dos dados (Carvalho, Fleury, \& Lopes, 2013).

Após uma primeira limpeza, que se concentrou em selecionar apenas artigos e revisões (excluindo materiais editoriais, livros e outros documentos menos úteis), chegou-se a uma base com 934 artigos publicados de 1977 a 2019. A estruturação da base de dados foi realizada na plataforma MS-Excel, visando organizar as informações mais relevantes, tais como autores, ano, título, palavraschave, periódico e número de citações, o que permite uma primeira interpretação de dados e possíveis limpezas necessárias.

Seguiu-se para o tratamento da base de dados por meio da geração de um ranking de relevância acadêmica. A utilização de número de citações isoladamente poderia gerar um viés nos dados, no qual artigos mais antigos naturalmente carregam maior número de citações do que os mais recentes. Para minimizar esse efeito, foi empregado um cálculo de ponderação que permitia os artigos serem mensurados como número de citações por ano, comumente empregado na construção dos fatores de impacto de periódicos acadêmicos (Uthman, Okwundu, Wiysonge, Young, \& Clarke, 2013), o que gerou uma emergência equilibrada de artigos recentes, mas com um número de citações relevantes para o seu grau relativo de novidade. Entende-se que essa estratégia minimiza o viés, apesar de não o eliminar, dado que artigos mais antigos também se beneficiam pelo efeito de rede que a sua disseminação acarreta.

Com o ranking gerado, foi adicionado um cálculo de participação do número de citações de cada artigo diante do número de citações total da amostra dos 934 artigos (usando o cálculo de média anual). A partir disso, pode-se buscar uma filtragem por meio de percentual acumulado: os artigos que representam $50 \%$ do número de citações (usando o cálculo de média anual) resultaram em uma amostra de 54 artigos. Leia-se: 54 artigos correspondem a 50\% do volume total de citações médias acumuladas presentes na amostra de 934 artigos, sendo esta uma Rev. Empreendedorismo Gest. Pequenas Empres. | São Paulo, v.9 | n.1 | p. 10-41 | Janeiro. 2020. 
estratégia efetiva para ranqueamento de relevância e priorização. Com esses 54 artigos sendo tratados como os mais relevantes da literatura, garantiu-se uma filtragem viável para análises de conteúdos robustas do panorama atual do tema.

Os trabalhos seguiram para leitura de abstracts visando à categorização e organização temática. Após isso, leituras e interpretações dos trabalhos foram realizadas, de modo a construir o referencial teórico do presente trabalho, bem como a análise de resultados, que será apresentada nas próximas seções.

\section{RESULTADOS DO ESTUDO}

Após o processo de filtragem, hierarquização e análise dos 54 principais artigos, foi realizada uma categorização deles de modo a compreender os campos de concentração da literatura atual. Tal categorização resultou em nove grupos principais:

1. Artigos referentes à relação entre Ensino de Empreendedorismo e intenção em empreender, com 15 trabalhos;

2. Artigos referentes aos processos de aprendizagem no Ensino de Empreendedorismo, com 8 trabalhos;

3. Artigos no formato de ensaio crítico sobre Ensino de Empreendedorismo, com 8 trabalhos;

4. Artigos fundamentados em revisões sistemáticas da literatura em Ensino de Empreendedorismo, com 7 trabalhos;

5. Artigos sobre boas práticas em sala de aula para Ensino de Empreendedorismo, com 6 trabalhos;

6. Artigos sobre estudos de gênero em Ensino de Empreendedorismo, com 3 trabalhos;

7. Artigos abordando Ensino de Empreendedorismo sob a ótica do reconhecimento de oportunidades, com 3 trabalhos;

8. Artigos sobre Ensino de Empreendedorismo no contexto de negócios sociais, com 3 trabalhos;

9. Artigos abordando Ensino de Empreendedorismo sob a visão baseada em competências, com 2 trabalhos. 
A distribuição temática pode ser analisada no gráfico a seguir.

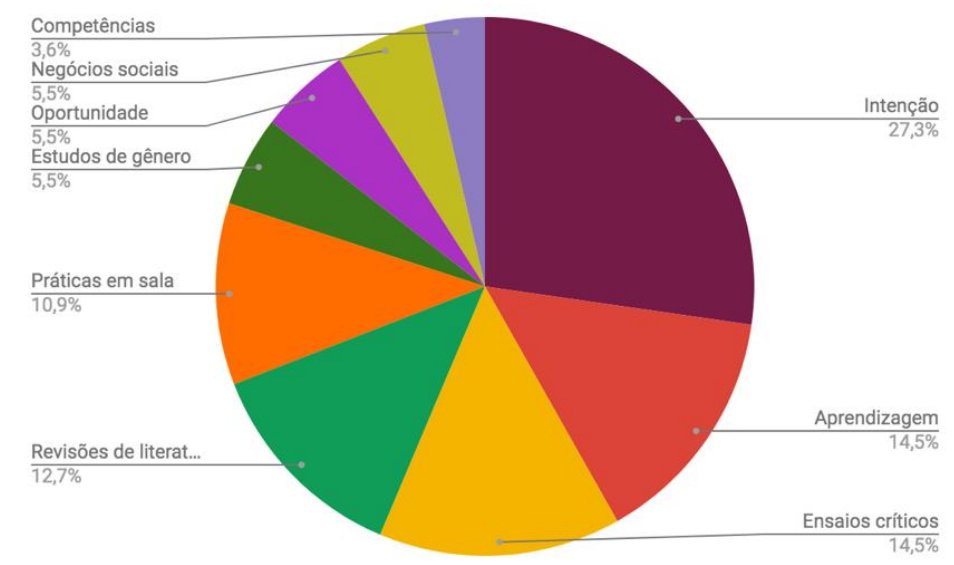

Figura 2: Distribuição das categorias identificadas Fonte: Elaborado pelos autores (2019).

Como pode ser percebido, o tópico de intenção em empreender (muitas vezes apontado como intenção empreendedora) representa mais de um quarto da amostra dos trabalhos. A principal justificativa encontrada é o fato de possuir uma série de artigos com maior crivo quantitativo, usualmente analisando o impacto após a vivência em um curso ou programa, por meio de coletas de dados, com alguns casos envolvendo análises longitudinais. Tal consistência possivelmente implica em um maior número de citações e replicabilidade de estudos, o que impacta no aumento de relevância do trabalho.

Cabe destacar que vários desses trabalhos são relativamente recentes, sendo mais de $50 \%$ deles publicados a partir de 2013 . Os principais trabalhos sobre o tema encontram-se na tabela abaixo:

Tabela 1: Principais artigos referentes à relação entre Ensino de Empreendedorismo e intenção em empreender.

\begin{tabular}{|l|l|c|}
\hline \multicolumn{1}{|c|}{ Autores (ano) } & \multicolumn{1}{c|}{ Título } & $\begin{array}{c}\text { Citações/ } \\
\text { ano }\end{array}$ \\
\hline $\begin{array}{l}\text { Souitaris, V; Zerbinati, } \\
\text { S; Al-Laham, A (2007) }\end{array}$ & $\begin{array}{l}\text { Do entrepreneurship programmes raise entrepreneurial } \\
\text { intention of science and engineering students? The effect of } \\
\text { learning, inspiration and resources }\end{array}$ & 47,5 \\
\hline $\begin{array}{l}\text { Bae, TJ; Qian, SS; } \\
\text { Miao, C; Fiet, JO } \\
(2014)\end{array}$ & $\begin{array}{l}\text { The Relationship Between Entrepreneurship Education and } \\
\text { Entrepreneurial Intentions: A Meta-Analytic Review }\end{array}$ & 42,2 \\
\hline $\begin{array}{l}\text { Oosterbeek, H; van } \\
\text { Praag, M; ljsselstein, A } \\
(2010)\end{array}$ & $\begin{array}{l}\text { The impact of entrepreneurship education on } \\
\text { entrepreneurship skills and motivation }\end{array}$ & 33,4 \\
\hline
\end{tabular}




\begin{tabular}{|l|l|c|}
\hline $\begin{array}{l}\text { Peterman, NE; } \\
\text { Kennedy, J (2003) }\end{array}$ & $\begin{array}{l}\text { Enterprise education: Influencing students' perceptions of } \\
\text { entrepreneurship }\end{array}$ & 31,3 \\
\hline $\begin{array}{l}\text { Fayolle, A; Gailly, B } \\
\text { (2015) }\end{array}$ & $\begin{array}{l}\text { The Impact of Entrepreneurship Education on } \\
\text { Entrepreneurial Attitudes and Intention: Hysteresis and } \\
\text { Persistence }\end{array}$ & 29,3 \\
\hline $\begin{array}{l}\text { Mcgee, JE; Peterson, } \\
\text { M; Mueller, SL; } \\
\text { Sequeira, JM (2009) }\end{array}$ & Entrepreneurial Self-Efficacy: Refining the Measure & 26,4 \\
\hline $\begin{array}{l}\text { von Graevenitz, G; } \\
\text { Harhoff, D; Weber, R } \\
\text { (2010) }\end{array}$ & The effects of entrepreneurship education & 20,8 \\
\hline $\begin{array}{l}\text { Nabi, G; Walmsley, A; } \\
\text { Linan, F; Akhtar, I; } \\
\text { Neame, C (2018) }\end{array}$ & $\begin{array}{l}\text { Does entrepreneurship education in the first year of higher } \\
\text { education develop entrepreneurial intentions? The role of } \\
\text { learning and inspiration }\end{array}$ & 16,0 \\
\hline $\begin{array}{l}\text { Linan, F; Rodriguez- } \\
\text { Cohard, JC; Rueda- } \\
\text { Cantuche, JM (2011) }\end{array}$ & $\begin{array}{l}\text { Factors affecting entrepreneurial intention levels: a role for } \\
\text { education }\end{array}$ & 15,9 \\
\hline $\begin{array}{l}\text { Rauch, A; Hulsink, W } \\
\text { (2015) }\end{array}$ & $\begin{array}{l}\text { Putting Entrepreneurship Education Where the Intention to } \\
\text { Act Lies: An Investigation Into the Impact of } \\
\text { Entrepreneurship Education on Entrepreneurial Behavior }\end{array}$ & 15,3 \\
\hline $\begin{array}{l}\text { Karimi, S; Biemans, } \\
\text { HJA; Lans, T; Chizari, } \\
\text { M; Mulder, M (2016) }\end{array}$ & $\begin{array}{l}\text { The Impact of Entrepreneurship Education: A Study of } \\
\text { Iranian Students' Entrepreneurial Intentions and Opportunity } \\
\text { Identification }\end{array}$ & 15,0 \\
\hline $\begin{array}{l}\text { Sanchez, JC (2013) } \\
\text { The Impact of an Entrepreneurship Education Program on } \\
\text { Entrepreneurial Competencies and Intention }\end{array}$ & 14,5 \\
\hline $\begin{array}{l}\text { Zhang, Y; Duysters, G; } \\
\text { Cloodt, M (2014) }\end{array}$ & $\begin{array}{l}\text { The role of entrepreneurship education as a predictor of } \\
\text { university students' entrepreneurial intention }\end{array}$ & 13,2 \\
\hline $\begin{array}{l}\text { Maresch, D; Harms, R; } \\
\text { Kailer, N; Wimmer- } \\
\text { Wurm, B (2016) }\end{array}$ & $\begin{array}{l}\text { The impact of entrepreneurship education on the } \\
\text { entrepreneurial intention of students in science and } \\
\text { engineering versus business studies university programs }\end{array}$ & 11,0 \\
\hline $\begin{array}{l}\text { Sanchez, JC (2011) } \\
\text { impact on intention of venture creation }\end{array}$ & 10,0 \\
\hline
\end{tabular}

Fonte: Elaborado pelos autores (2019).

Um segundo campo de maior atenção é o dos processos de aprendizagem, que usualmente analisa questões como mentalidade e fatores contextuais para a disposição de empreender. Os principais trabalhos sobre o tema encontram-se na tabela abaixo:

Tabela 2: Principais artigos referentes aos processos de aprendizagem no Ensino de Empreendedorismo

\begin{tabular}{|l|l|c|}
\hline \multicolumn{1}{|c|}{ Autores (ano) } & \multicolumn{1}{|c|}{ Título } & $\begin{array}{c}\text { Citações/ } \\
\text { ano }\end{array}$ \\
\hline Cope, J (2005) & $\begin{array}{l}\text { Toward a dynamic learning perspective of entrepreneurship } \\
\text { Cope, J (2011) }\end{array}$ & $\begin{array}{l}\text { Entrepreneurial learning from failure: An interpretative } \\
\text { phenomenological analysis }\end{array}$ \\
\hline Politis, D (2005) & $\begin{array}{l}\text { The process of entrepreneurial learning: A conceptual } \\
\text { framework }\end{array}$ & 25,4 \\
\hline $\begin{array}{l}\text { Wang, CL; Chugh, H } \\
\text { (2014) }\end{array}$ & $\begin{array}{l}\text { Entrepreneurial Learning: Past Research and Future } \\
\text { Challenges }\end{array}$ & 25,3 \\
\hline Cope, J (2003) & $\begin{array}{l}\text { Entrepreneurial learning and critical reflection - } \\
\text { Discontinuous events as triggers for 'higher-level' learning }\end{array}$ & 18,0 \\
\hline $\begin{array}{l}\text { Gompers, P; Lerner, J; } \\
\text { Scharfstein, D (2005) }\end{array}$ & $\begin{array}{l}\text { Entrepreneurial spawning: Public corporations and the } \\
\text { genesis of new ventures, 1986 to 1999 }\end{array}$ & 14,6 \\
\hline Holcomb, TR; Ireland, & Architecture of Entrepreneurial Learning: Exploring the Link & 13,2 \\
\hline
\end{tabular}




\begin{tabular}{|l|l|c|}
\hline $\begin{array}{l}\text { RD; Holmes, RM; Hitt, } \\
\text { MA (2009) }\end{array}$ & Among Heuristics, Knowledge, and Action & \\
\hline $\begin{array}{l}\text { Harrison, R; Leitch, CM } \\
\text { (2005) }\end{array}$ & $\begin{array}{l}\text { Entrepreneurial learning: Researching the interface between } \\
\text { learning and the entrepreneurial context }\end{array}$ & 10,1 \\
\hline
\end{tabular}

Fonte: Elaborado pelos autores (2019).

Os ensaios críticos, trabalhos usualmente apresentados como reflexões pessoais ou proposição de modelos sem estabelecimento de métodos, também são bastante citados na literatura. Alguns deles, como o de Fayolle (2013), são sustentados por trabalhos anteriores, sendo uma conclusão pessoal dos resultados encontrados. Outros já trazem um tom provocativo, convocando pesquisadores e comunidades a se atentarem a algum tópico ou tendência, como é o caso do trabalho de Hisrich, Langan-Fox e Grant (2007). Os principais trabalhos sobre o tema encontram-se na tabela abaixo:

Tabela 3: Principais artigos no formato de ensaio crítico sobre Ensino de Empreendedorismo

\begin{tabular}{|l|l|c|}
\hline \multicolumn{1}{|c|}{ Autores (ano) } & \multicolumn{1}{|c|}{ Título } & $\begin{array}{c}\text { Citações/ } \\
\text { ano }\end{array}$ \\
\hline Fayolle, A (2013) & Personal views on the future of entrepreneurship education & 21,7 \\
\hline Gibb, A (2002) & $\begin{array}{l}\text { In pursuit of a new 'enterprise' and 'entrepreneurship' } \\
\text { paradigm for learning: creative destruction, new values, new } \\
\text { ways of doing things and new combinations of knowledge }\end{array}$ & 16,8 \\
\hline O'Connor, A (2013) & $\begin{array}{l}\text { A conceptual framework for entrepreneurship education } \\
\text { policy: Meeting government and economic purposes }\end{array}$ & 13,5 \\
\hline $\begin{array}{l}\text { Bullough, A; Renko, M; } \\
\text { Myatt, T (2014) }\end{array}$ & $\begin{array}{l}\text { Danger Zone Entrepreneurs: The Importance of Resilience } \\
\text { and Self-Efficacy for Entrepreneurial Intentions }\end{array}$ & 12,8 \\
\hline Zhou, L (2007) & $\begin{array}{l}\text { The effects of entrepreneurial proclivity and foreign market } \\
\text { knowledge on early internationalization }\end{array}$ & 11,4 \\
\hline Duval-Couetil, N (2013) & $\begin{array}{l}\text { Assessing the Impact of Entrepreneurship Education } \\
\text { Programs: Challenges and Approaches }\end{array}$ & 9,7 \\
\hline $\begin{array}{l}\text { Hisrich, R; Langan-Fox, } \\
\text { J; Grant, S (2007) }\end{array}$ & $\begin{array}{l}\text { Entrepreneurship research and practice - A call to action for } \\
\text { psychology }\end{array}$ & 9,5 \\
\hline $\begin{array}{l}\text { Edelman, LF; } \\
\text { Manolova, TS; Brush, } \\
\text { CG (2008) }\end{array}$ & $\begin{array}{l}\text { Entrepreneurship education: Correspondence between } \\
\text { practices of nascent entrepreneurs and textbook } \\
\text { prescriptions for success }\end{array}$ & 9,0 \\
\hline Fons: Erabs & \\
\hline
\end{tabular}

Fonte: Elaborado pelos autores (2019).

Revisões de literatura cobrem um pouco mais de $12 \%$ dos principais artigos do ranking. Nesses artigos, encontram-se os clássicos de Kuratko (2005) e Katz (2003), assim como metanálises que influenciaram bastante a pesquisa em Ensino de Empreendedorismo, como o trabalho de Martin, McNally e Kay (2013). Os principais trabalhos sobre o tema encontram-se na tabela abaixo: 
Tabela 4: Principais artigos fundamentados em revisões sistemáticas da literatura em Ensino de Empreendedorismo

\begin{tabular}{|l|l|c|}
\hline \multicolumn{1}{|c|}{ Autores (ano) } & \multicolumn{1}{c|}{ Título } & $\begin{array}{c}\text { Citações/ } \\
\text { ano }\end{array}$ \\
\hline Kuratko, DF (2005) & $\begin{array}{l}\text { The emergence of entrepreneurship education: } \\
\text { Development, trends, and challenges }\end{array}$ & 45,7 \\
\hline $\begin{array}{l}\text { Martin, BC; McNally, } \\
\text { JJ; Kay, MJ (2013) }\end{array}$ & $\begin{array}{l}\text { Examining the formation of human capital in } \\
\text { entrepreneurship: A meta-analysis of entrepreneurship } \\
\text { education outcomes }\end{array}$ & 39,5 \\
\hline $\begin{array}{l}\text { Pittaway, L; Cope, J } \\
\text { (2007) }\end{array}$ & $\begin{array}{l}\text { Entrepreneurship education - A systematic review of the } \\
\text { evidence }\end{array}$ & 33,0 \\
\hline Katz, JA (2003) & $\begin{array}{l}\text { The chronology and intellectual trajectory of American } \\
\text { entrepreneurship education 1876-1999 }\end{array}$ & 26,1 \\
\hline $\begin{array}{l}\text { Nabi, G; Linan, F; } \\
\text { Fayolle, A; Krueger, N; } \\
\text { Walmsley, A (2017) }\end{array}$ & $\begin{array}{l}\text { The Impact of Entrepreneurship Education in Higher } \\
\text { Education: A Systematic Review and Research Agenda }\end{array}$ & 22,5 \\
\hline $\begin{array}{l}\text { Rideout, EC; Gray, DO } \\
\text { (2013) }\end{array}$ & $\begin{array}{l}\text { Does Entrepreneurship Education Really Work? A Review } \\
\text { and Methodological Critique of the Empirical Literature on } \\
\text { the Effects of University-Based Entrepreneurship Education }\end{array}$ & 16,8 \\
\hline $\begin{array}{l}\text { Bechard, JP; Gregoire, } \\
\text { D (2005) }\end{array}$ & $\begin{array}{l}\text { Entrepreneurship education research revisited: The case of } \\
\text { higher education }\end{array}$ & 9,6 \\
\hline
\end{tabular}

Fonte: Elaborado pelos autores (2019).

Os trabalhos exclusivamente voltados para a apresentação de boas práticas em sala de aula compõem cerca de 10\% do ranking. Esse tópico mostrou-se como o mais difícil de categorizar, visto que muitos trabalhos sobre intenção de empreender também apresentam boas práticas em sala de aula (eles foram separados pela ênfase singular na medição do impacto em intenção).

Outra dificuldade na categorização foi, por exemplo, o trabalho de Neck e Greene (2011), que pode ser considerado como um ensaio crítico (visão pessoal não sustentada por um método explícito), mas que foi categorizado como boas práticas por entrar em detalhes nas abordagens pedagógicas de alguns cursos. Os principais trabalhos sobre o tema encontram-se na tabela abaixo:

Tabela 5: Principais artigos sobre boas práticas em sala de aula para Ensino de Empreendedorismo

\begin{tabular}{|c|c|c|}
\hline Autores (ano) & Título & $\begin{array}{l}\text { Citações/ } \\
\text { ano }\end{array}$ \\
\hline $\begin{array}{l}\text { Neck, HM; Greene, } \\
\text { PG (2011) }\end{array}$ & $\begin{array}{l}\text { Entrepreneurship Education: Known Worlds and New } \\
\text { Frontiers }\end{array}$ & 35,5 \\
\hline Honig, B (2004) & $\begin{array}{l}\text { Entrepreneurship Education: Toward a Model of Contingency- } \\
\text { Based Business Planning }\end{array}$ & 21,6 \\
\hline $\begin{array}{l}\text { Piperopoulos, P; } \\
\text { Dimov, D (2015) }\end{array}$ & $\begin{array}{l}\text { Burst Bubbles or Build Steam? Entrepreneurship Education, } \\
\text { Entrepreneurial Self-Efficacy, and Entrepreneurial Intentions }\end{array}$ & 19,5 \\
\hline $\begin{array}{l}\text { Pittaway, L; Cope, J } \\
\text { (2007) }\end{array}$ & $\begin{array}{l}\text { Simulating entrepreneurial learning - Integrating experiential } \\
\text { and collaborative approaches to learning }\end{array}$ & 14,1 \\
\hline $\begin{array}{l}\text { Rasmussen, EA; } \\
\text { Sorheim, R (2006) }\end{array}$ & Action-based entrepreneurship education & 13,7 \\
\hline Gielnik et al. (2015) & $\begin{array}{l}\text { Action and Action-Regulation in Entrepreneurship: Evaluating } \\
\text { a Student Training for Promoting Entrepreneurship }\end{array}$ & 10 \\
\hline
\end{tabular}

Fonte: Elaborado pelos autores (2019). 
Os estudos de gênero demonstram maior sofisticação por parte dos trabalhos, dando emergência a novos moderadores, no caso, o gênero, para se analisar a efetividade de abordagens em ensino de empreendedorismo para contextos específicos. Cabe destaque o trabalho de Wilson, Kickul e Marlino (2007). Os autores atuaram como um "abre-alas" nessa vertente ao demonstrarem que mulheres participantes de um programa específico demonstraram maior autoeficácia que homens após a vivência. Os principais trabalhos sobre o tema encontram-se na tabela abaixo:

Tabela 6: Principais artigos sobre estudos de gênero em Ensino de Empreendedorismo

\begin{tabular}{|l|l|c|}
\hline \multicolumn{1}{|c|}{ Autores (ano) } & \multicolumn{1}{|c|}{ Título } & $\begin{array}{c}\text { Citações/ } \\
\text { ano }\end{array}$ \\
\hline $\begin{array}{l}\text { Wilson, F; Kickul, J; } \\
\text { Marlino, D (2007) }\end{array}$ & $\begin{array}{l}\text { Gender, entrepreneurial self-efficacy, and entrepreneurial } \\
\text { career intentions: Implications for entrepreneurship education }\end{array}$ & 39,3 \\
\hline $\begin{array}{l}\text { Hoogendoorn, S; } \\
\begin{array}{l}\text { Oosterbeek, H; van } \\
\text { Praag, M (2013) }\end{array}\end{array}$ & $\begin{array}{l}\text { The Impact of Gender Diversity on the Performance of } \\
\text { Business Teams: Evidence from a Field Experiment }\end{array}$ & 10 \\
\hline $\begin{array}{l}\text { Westhead, P; } \\
\text { Solesvik, MZ (2016) }\end{array}$ & $\begin{array}{l}\text { Entrepreneurship education and entrepreneurial intention: Do } \\
\text { female students benefit? }\end{array}$ & 10 \\
\hline
\end{tabular}

Fonte: Elaborado pelos autores (2019).

Foram identificados trabalhos que se concentraram no tópico "reconhecimento de oportunidades", vertente explorada após o seminal artigo de Shane e Venkataraman, cuja provocação central era a de que a existência e o reconhecimento de oportunidades eram necessários para a existência de empreendedorismo. Os principais trabalhos sobre o tema encontram-se na tabela abaixo:

Tabela 7: Principais artigos abordando Ensino de Empreendedorismo sob a ótica do reconhecimento de oportunidades

\begin{tabular}{|l|l|c|}
\hline \multicolumn{1}{|c|}{ Autores (ano) } & \multicolumn{1}{c|}{ Título } & $\begin{array}{c}\text { Citações/ } \\
\text { ano }\end{array}$ \\
\hline Baron, RA (2006) & $\begin{array}{l}\text { Opportunity recognition as pattern recognition: How } \\
\text { entrepreneurs "connect the dots" to identify new business } \\
\text { opportunities }\end{array}$ & 29,1 \\
\hline $\begin{array}{l}\text { Levie, J; Autio, E } \\
\text { (2008) }\end{array}$ & A theoretical grounding and test of the GEM model & 14,1 \\
\hline $\begin{array}{l}\text { DeTienne, DR; } \\
\text { Chandler, GN (2004) }\end{array}$ & $\begin{array}{l}\text { Opportunity Identification and Its Role in the Entrepreneurial } \\
\text { Classroom: A Pedagogical Approach and Empirical Test }\end{array}$ & 13,6 \\
\hline
\end{tabular}

Fonte: Elaborado pelos autores (2019). 
Outra categoria que surgiu com atenção a contextos específicos foi a de negócios sociais, cujos principais trabalhos analisaram o impacto de cursos e treinamentos para essa realidade. No caso do trabalho de Smith, Gonin e Besharov (2013), foram encontradas apenas menções sobre universidades e cursos de empreendedorismo nesse cenário, mas o artigo foi mantido por apresentar o contexto e o ensino de empreendedorismo no âmbito de negócios sociais como um tópico para estudos futuros. Os principais trabalhos sobre o tema encontram-se na tabela abaixo:

Tabela 8: Principais artigos sobre Ensino de Empreendedorismo no contexto de negócios sociais.

\begin{tabular}{|l|l|c|}
\multicolumn{1}{|c|}{ Autores (ano) } & \multicolumn{1}{|c|}{ Título } & $\begin{array}{c}\text { Citações/ } \\
\text { ano }\end{array}$ \\
\hline $\begin{array}{l}\text { Smith, WK; Gonin, } \\
\text { M; Besharov, ML } \\
(2013)\end{array}$ & $\begin{array}{l}\text { Managing Social-Business Tensions: A Review and Research } \\
\text { Agenda for Social Enterprise }\end{array}$ & 25,5 \\
\hline $\begin{array}{l}\text { Karlan, D; Valdivia, } \\
\text { M (2011) }\end{array}$ & $\begin{array}{l}\text { Teaching Entrepreneurship: Impact of Business Training on } \\
\text { Microfinance Clients and Institutions }\end{array}$ & 21 \\
\hline $\begin{array}{l}\text { Nga, JKH; } \\
\text { Shamuganathan, G } \\
(2010)\end{array}$ & $\begin{array}{l}\text { The Influence of Personality Traits and Demographic Factors } \\
\text { on Social Entrepreneurship Start Up Intentions }\end{array}$ & 12,6 \\
\hline
\end{tabular}

Fonte: Elaborado pelos autores (2019).

Por fim, a visão baseada em competências foi colocada como uma categoria por ser uma possibilidade de tendência futura e ter arcabouços específicos. É considerada a possibilidade de agregar este tópico na categoria de aprendizagem, visto que os trabalhos versam sobre conceitos similares. Os principais trabalhos sobre o tema encontram-se na tabela abaixo:

Tabela 9: Principais artigos abordando Ensino de Empreendedorismo sob a visão baseada em competências

\begin{tabular}{|l|l|c|}
\hline Autores (ano) & Título & $\begin{array}{l}\text { Citações/ } \\
\text { ano }\end{array}$ \\
\hline $\begin{array}{l}\text { Morris, MH; Webb, } \\
\text { JW; Fu, J; Singhal, S } \\
\text { (2013) }\end{array}$ & $\begin{array}{l}\text { A Competency-Based Perspective on Entrepreneurship } \\
\text { Education: Conceptual and Empirical Insights }\end{array}$ & 15 \\
\hline $\begin{array}{l}\text { Lans, T; Blok, V; } \\
\text { Wesselink, R (2014) }\end{array}$ & $\begin{array}{l}\text { Learning apart and together: towards an integrated } \\
\text { competence framework for sustainable entrepreneurship in } \\
\text { higher education }\end{array}$ & 14 \\
\hline
\end{tabular}

Fonte: Elaborado pelos autores (2019). 


\section{DISCUSSÕES}

Apresentado o panorama de artigos na seção de resultados, cabe a discussão sobre tendências e perspectivas futuras. Esta seção divide-se em três tópicos: 1) as pesquisas sobre abordagem em sala de aula; 2) as pesquisas sobre 0 ecossistema de ensino; e 3) temas emergentes.

\subsection{O Ensino de Empreendedorismo em Sala de Aula}

No contexto do Ensino de Empreendedorismo dentro de sala de aula, algumas oportunidades de pesquisa apresentam-se como a exploração das ações com maior detalhamento e as abordagens baseadas em experiências. Diferentes abordagens, inclusive diferentes professores, impactam nos resultados de um curso, podendo ser este o motivo para resultados distintos quando é avaliado o impacto de cursos (Martin, McNally, \& Kay, 2013). O detalhamento permitiria a identificação de potenciais mediadores e moderadores, além de se mostrar útil para professores interessados na melhoria de suas práticas.

A atenção no ensino de empreendedorismo baseado em experiências (experiential learning) e em problemas mostra-se bastante presente na literatura (McNally, Honig, \& Martin, 2018; Nabi et al., 2017; Taatila, 2010) com artigos recentes, embora não presentes no ranking. Esses artigos analisam contextos específicos de cursos na graduação baseados em experiências e projetos práticos, como em programas do MIT (Ribeiro, Uechi, \& Plonski, 2018) e Berkeley (Sidhu, Singer, Suoranta, \& Johnsson, 2014). Tal chamamento por detalhes e ações concretas não se limita ao contexto de ensino de empreendedorismo, mas ao de universidades empreendedoras em geral (Guerrero, Urbano, Fayolle, Klofsten, \& Mian, 2016).

\subsection{O Ensino de Empreendedorismo baseado em Ecossistemas e os} Estudantes como Atores no Processo de Formação

O segundo aspecto da discussão é a perspectiva de uma visão baseada em ecossistemas, na qual os alunos são formados não somente pelos cursos da grade curricular, mas também pelas vivências no ambiente de ensino, como empresas Rev. Empreendedorismo Gest. Pequenas Empres. | São Paulo, v.9 | n.1 | p. 10-41 | Janeiro. 2020. 
juniores, atlética e centros acadêmicos (Moraes, lizuka, \& Pedro, 2018; Ribeiro et al., 2018; Padilla-Angulo, 2019; Ferreira, \& Freitas, 2014; Politis, 2005).

Conforme apontado por Hindle (2007) no Handbook of Research in Entrepreneurship Education, a educação para o empreendedorismo pode ser definida como uma atividade voltada à transferência de conhecimento, estimulando a criação de bens e serviços a partir da exploração de oportunidades, independente de como se dá o esforço, por quem ele é ofertado e com quais efeitos. Tal definição retira a responsabilidade da educação exclusivamente dos professores em salas de aula, abrindo possibilidades para todo um ecossistema de formação de empreendedores nas universidades.

Segundo Preedy e Jones (2015), uma abordagem interdepartamental, bem como atividades extracurriculares, mostram-se mais efetivas no desenvolvimento de competências e motivação para empreender. Sendo esta a provocação da pergunta de pesquisa, entende-se que a maioria dos trabalhos concentra-se apenas em análises de cursos e propostas em sala de aula, com grande influência da relação de professor-aluno.

Como defendido por Etzkowitz (2013), a abordagem excessivamente centrada no papel dos agentes institucionais dando suporte a empreendedorismo é arriscada, podendo se tornar negligente quanto a mecanismos modernos propostos pelos próprios estudantes de modo autônomo. O autor apresenta o caso de um mecanismo de suporte criado em Stanford pelos próprios alunos de graduação que foi capaz de superar as atividades negligenciadas pela Universidade no suporte à criação de startups:

\footnotetext{
Unrealized capabilities, hidden behind a bureaucratic maxim for legitimating the status quo: 'if it's not broken, don't fix it', were brought to light by StartX, an extra-curricular student-originated experiential entrepreneurship education and mentoring initiative, based on a converse premise: 'If it's working well, make it better.' (Etzkowitz, 2013, p. 608).
}

Desse modo, os resultados reforçam que a lacuna levantada por tais estudos ainda carece de um maior volume de estudos e de uma atenção capaz de posicionar esse tipo de debate entre os artigos mais relevantes da área. O estudante como ator central do processo de formação de empreendedores é um tema tratado há décadas. O livro "Sustaining Change in Universities", do sociólogo Burton Clark, defende o papel das student-led organizations e os movimentos grassroots na 
transformação das universidades para dar suporte a empreendedores. O conceito de movimentos grassroots (mecanismos de suporte criados pelos próprios alunos e ganhando relevância institucional), em um processo de transformação de cima para baixo, mostra-se como uma relevante tendência para pesquisas. Tal fenômeno ocorre não somente globalmente, como em Stanford, MIT e Reino Unido, mas também em contextos nacionais, como apresentam Ribeiro e Plonski (2019), com casos na Unicamp e Universidade de São Paulo (USP).

\subsection{Temas Emergentes em Ensino de Empreendedorismo}

Sobre temas emergentes, há duas categorias de negócios sociais e questões de gênero. Ambas caracterizam-se pela provocação de que contextos específicos podem implicar em resultados diferentes, sendo necessário o seu aprofundamento para melhor desenho de programas que não excluam ou prejudiquem participantes.

A necessidade de explorar as abordagens e estimular modelos de ensino em empreendedorismo que considere os debates de gênero é algo fundamental para o contexto brasileiro, no qual, dos 16 fundadores de startups unicórnio (valor de mercado acima de um bilhão de dólares), tem-se apenas uma mulher (Naoe, 2019).

A análise de implicações entre gênero e autoeficácia pode trazer novas fronteiras nos estudos sobre ensino de empreendedorismo, permitindo leituras robustas e delineamentos sofisticados de programas. O horizonte futuro é a existência de trabalhos que saiam do modelo "one size fits all" e comecem a valorizar o papel do contexto na formação de empreendedores. Nabi et al. (2017) destacam, por exemplo, trabalhos que identificaram contextos específicos com moderadores duplos (double-moderator effect), no qual cultura e gênero, quando combinados, geram resultados distintos do esperado.

Um caso reconhecido é o trabalho de Packham, Jones, Miller, Pickernell e Thomas (2010), que encontrou tal fenômeno onde o ensino de empreendedorismo afetou negativamente a intenção em empreender no contexto específico de estudantes homens na Alemanha. Gielnik et al. (2015) também reforçam a necessidade de aprofundamento para contextos específicos e suas pesquisas, que analisam o contexto na África, já encontram-se na lista de artigos mais relevantes. 


\section{CONCLUSÕES}

O presente trabalho teve como objetivo analisar o panorama da literatura acadêmica em ensino de empreendedorismo, refletindo acerca de horizontes futuros, de modo a orientar educadores, administradores e pesquisadores a refletirem acerca de suas práticas e abordagens.

A utilização do método de revisão sistemática de literatura com análise de conteúdo permitiu uma exploração dos principais tópicos tratados, assim como antever potenciais horizontes para pesquisa na área. Cabe ressaltar que parcela expressiva da literatura relevante concentra-se em abordagens em sala de aula, 0 que sugere que a academia ainda não apresenta atenção às mudanças identificadas na introdução do trabalho.

O artigo contribui com a teoria em organizar os debates sobre ensino de empreendedorismo e identificação de tendências, assim como colabora com a prática ao apresentar um racional para professores e administradores ligados ao tema. Como limitações e propostas para trabalhos futuros, entende-se que 0 aprofundamento com análises bibliométricas, como proposto por Gomes, Facin, Salerno e Ikenami (2018), pode ser um esforço frutífero.

\section{REFERÊNCIAS BIBLIOGRÁFICAS}

Bae, T. J., Qian, S., Miao, C., \& Fiet, J. O. (2014). The relationship between entrepreneurship education and entrepreneurial intentions: A meta-analytic review. Entrepreneurship Theory and Practice, v. 38, n. 2, pp. 217-254.

Baron, R. A. (2006). Opportunity recognition as pattern recognition: How entrepreneurs "connect the dots" to identify new business opportunities. Academy of Management Perspectives, v. 20, n. 1, pp. 104-119.

Béchard, J. P., \& Grégoire, D. (2005). Entrepreneurship education research revisited: The case of higher education. Academy of Management Learning \& Education, v. 4, n. 1, pp. 22-43.

Bullough, A., Renko, M., \& Myatt, T. (2014). Danger Zone Entrepreneurs: The Importance of Resilience and Self-Efficacy for Entrepreneurial Intentions. Entrepreneurship Theory and Practice, v. 38, n. 3, pp. 473-499. 
Carvalho, M., Fleury, A., \& Lopes, A. P. (2013). An overview of the literature on technology roadmapping (TRM): Contributions and trends. Technological Forecasting and Social Change, v. 80, n. 7, pp. 1418-1437.

Cooper, R. G. (2009). How companies are reinventing their idea-to-launch methodologies. Research Technology Management, v. 52, n. 2, p. 47-57.

Corbett, A. (2005). Universities and the Europe of knowledge: Ideas, institutions and policy entrepreneurship in European Union Higher Education Policy, Palgrave MacMillan, New York.

Cope, J. (2011). Entrepreneurial learning from failure: An interpretative phenomenological analysis. Journal of Business Venturing, v. 26, n. 6, pp. 604-623.

Cope, J. (2005). Toward a dynamic learning perspective of entrepreneurship. Entrepreneurship Theory and Practice, v. 29, n. 4, pp. 373-397.

Cope, J. (2003). Entrepreneurial learning and critical reflection: Discontinuous events as triggers for 'higher-level'learning. Management Learning, v. 34, n. 4, pp. 429-450.

Duval-Couetil, N. (2013). Assessing the impact of entrepreneurship education programs: Challenges and approaches. Journal of Small Business Management, v. 51 , n. 3, pp. 394-409.

Edelman, L. F., Manolova, T. S., \& Brush, C. G. (2008). Entrepreneurship education: Correspondence between practices of nascent entrepreneurs and textbook prescriptions for success. Academy of Management Learning \& Education, v. 7, n. 1, pp. 56-70.

DeTienne, D. R., \& Chandler, G. N. (2004). Opportunity identification and its role in the entrepreneurial classroom: A pedagogical approach and empirical test. Academy of Management Learning \& Education, v. 3, n. 3, pp. 242-257. 
Etzkowitz, H. (2013). StartX and the 'paradox of success': filling the gap in Stanford's entrepreneurial culture. Social Science Information, v. 52, n. 4, pp. 605-627.

Fayolle, A. (2013). Personal views on the future of entrepreneurship education. Entrepreneurship \& Regional Development, v. 25, n. 7-8, pp. 692-701.

Fayolle, A., \& Gailly, B. (2015). The impact of entrepreneurship education on entrepreneurial attitudes and intention: Hysteresis and persistence. Journal of Small Business Management, v. 53, n. 1, pp. 75-93.

Ferreira, E. R. A., \& de Freitas, A. A. F. (2014). Propensão empreendedora entre estudantes participantes de empresas juniores. Revista de Empreendedorismo e Gestão de Pequenas Empresas, v. 2, n. 3, pp. 3-32.

Frese, M. (2009). Towards a psychology of entrepreneurship-an action theory perspective. Foundations and Trends $\AA$ in Entrepreneurship, v. 5, n. 6, pp. 437-496.

Gibb, A. (2002). In pursuit of a new 'enterprise'and 'entrepreneurship'paradigm for learning: creative destruction, new values, new ways of doing things and new combinations of knowledge. International Journal of Management Reviews, v. 4, n. 3, pp. 233-269.

Gielnik, M. M., Frese, M., Kahara-Kawuki, A., Wasswa Katono, I., Kyejjusa, S., Ngoma, M., \& Oyugi, J. (2015). Action and action-regulation in entrepreneurship: Evaluating a student training for promoting entrepreneurship. Academy of Management Learning \& Education, v. 14, n. 1, pp. 69-94.

Gomes, L. A. V., Facin, A. L. F., Salerno, M. S., \& Ikenami, R. K. (2018). Unpacking the innovation ecosystem construct: Evolution, gaps and trends. Technological Forecasting and Social Change, v. 136, pp. 30-48. 
Gompers, P., Lerner, J., \& Scharfstein, D. (2005). Entrepreneurial spawning: Public corporations and the genesis of new ventures, 1986 to 1999. The Journal of Finance, v. 60, n. 2, pp. 577-614.

Guerrero, M., Urbano, D., Fayolle, A., Klofsten, M., \& Mian, S. (2016) Entrepreneurial universities: emerging models in the new social and economic landscape. Small Business Economics, v. 47, n. 3, pp. 551-563

Harrison, R. T., \& Leitch, C. M. (2005). Entrepreneurial learning: Researching the interface between learning and the entrepreneurial context. Entrepreneurship Theory and Practice, v. 29, n. 4, pp. 351-371.

Hindle, K. (2007). Teaching entrepreneurship at university: from the wrong building to the right philosophy. Handbook of Research in Entrepreneurship Education, v. 1, pp. 104-126.

Hisrich, R., Langan-Fox, J., \& Grant, S. (2007). Entrepreneurship research and practice: a call to action for psychology. American Psychologist, v. 62, n. 6, pp. 575.

Holcomb, T. R., Ireland, R. D., Holmes Jr., R. M., \& Hitt, M. A. (2009). Architecture of entrepreneurial learning: Exploring the link among heuristics, knowledge, and action. Entrepreneurship Theory and Practice, v. 33, n. 1, pp. 167-192.

Honig, B. (2004). Entrepreneurship education: Toward a model of contingency-based business planning. Academy of Management Learning \& Education, v. 3, n. 3, pp. 258-273.

Hoogendoorn, S., Oosterbeek, H., \& Van Praag, M. (2013). The impact of gender diversity on the performance of business teams: Evidence from a field experiment. Management Science, v. 59, n. 7, pp. 1514-1528.

Jack, S.L., \& Anderson, A.R. (2002). The effects of embeddedness on the entrepreneurial process. Journal of Business Venturing, v. 17 n. 5, pp. 467-87. 
Katz, J. A. (2003). The chronology and intellectual trajectory of American entrepreneurship education: 1876-1999. Journal of Business Venturing, v. 18, n. 2, pp. 283-300.

Karlan, D., \& Valdivia, M. (2011). Teaching entrepreneurship: Impact of business training on microfinance clients and institutions. Review of Economics and Statistics, v. 93, n. 2, pp. 510-527.

Karimi, S., Biemans, H. J., Lans, T., Chizari, M., \& Mulder, M. (2016). The impact of entrepreneurship education: A study of Iranian students' entrepreneurial intentions and opportunity identification. Journal of Small Business Management, v. 54, n. 1, pp. 187-209.

Kuratko, D. F. (2005). The emergence of entrepreneurship education: Development, trends, and challenges. Entrepreneurship Theory and Practice, v. 29, n. 5, pp. 577597.

Lans, T., Blok, V., \& Wesselink, R. (2014). Learning apart and together: towards an integrated competence framework for sustainable entrepreneurship in higher education. Journal of Cleaner Production, v. 62, pp. 37-47.

Levie, J., \& Autio, E. (2008). A theoretical grounding and test of the GEM model. Small Business Economics, v. 31, n. 3, pp. 235-263.

Liñán, F., Rodríguez-Cohard, J. C., \& Rueda-Cantuche, J. M. (2011). Factors affecting entrepreneurial intention levels: a role for education. International Entrepreneurship and Management Journal, v. 7, n. 2, pp. 195-218.

Maresch, D., Harms, R., Kailer, N., \& Wimmer-Wurm, B. (2016). The impact of entrepreneurship education on the entrepreneurial intention of students in science and engineering versus business studies university programs. Technological Forecasting and Social Change, v. 104, pp. 172-179. 
Maritz, A., \& Brown, C. R. (2013). Illuminating the black box of entrepreneurship education programs. Education+Training, v. 55, n. 3, pp. 234-252.

Martin, B. C., McNally, J. J., \& Kay, M. J. (2013). Examining the formation of human capital in entrepreneurship: A meta-analysis of entrepreneurship education outcomes. Journal of Business Venturing, v. 28, n. 2, pp. 211-224.

McGee, J. E., Peterson, M., Mueller, S. L., \& Sequeira, J. M. (2009). Entrepreneurial self-efficacy: refining the measure. Entrepreneurship Theory and Practice, v. 33, n. 4, pp. 965-988.

McNally, J., Honig, B., \& Martin, B. (2018). A Preliminary Exploration of the Development of Wisdom in Entrepreneurship Education. Revista de Empreendedorismo e Gestão de Pequenas Empresas, v. 7, n. 1, pp. 01-34.

Moraes, G. H. S. M. D., lizuka, E. S., \& Pedro, M. (2018). Effects of entrepreneurial characteristics and university environment on entrepreneurial intention. Revista de Administração Contemporânea, v. 22, n. 2, pp. 226-248.

Morris, M. H., Webb, J. W., Fu, J., \& Singhal, S. (2013). A competency-based perspective on entrepreneurship education: conceptual and empirical insights. Journal of Small Business Management, v. 51, n. 3, pp. 352-369.

Nabi, G., Liñán, F., Fayolle, A., Krueger, N., \& Walmsley, A. (2017). The impact of entrepreneurship education in higher education: $A$ systematic review and research agenda. Academy of Management Learning \& Education, v. 16, n. 2, pp. 277-299.

Nabi, G., Walmsley, A., Liñán, F., Akhtar, I., \& Neame, C. (2018). Does entrepreneurship education in the first year of higher education develop entrepreneurial intentions? The role of learning and inspiration. Studies in Higher Education, v. 43, n. 3, pp. 452-467. 
Naoe, A. (2019) 99, Nubank e mais: USP formou dez dos 16 fundadores de unicórnios do Brasil. Uol Notícias - Tecnologia. Disponível em:

<https://noticias.uol.com.br/tecnologia/noticias/redacao/2019/05/12/99-nubank-emais-usp-formou-dez-dos-16-fundadores-de-unicornios-do-brasil.htm>. Acesso em: 14 mai. 2019.

Neck, H. M., \& Greene, P. G. (2011). Entrepreneurship education: known worlds and new frontiers. Journal of Small Business Management, v. 49, n. 1, pp. 55-70.

Nga, J. K. H., \& Shamuganathan, G. (2010). The influence of personality traits and demographic factors on social entrepreneurship start up intentions. Journal of Business Ethics, v. 95, n. 2, pp. 259-282.

O'Connor, A. (2013). A conceptual framework for entrepreneurship education policy: Meeting government and economic purposes. Journal of Business Venturing, v. 28, n. 4 , pp. 546-563.

Oosterbeek, H., Van Praag, M., \& ljsselstein, A. (2010). The impact of entrepreneurship education on entrepreneurship skills and motivation. European Economic Review, v. 54, n. 3, pp. 442-454.

Packham, G., Jones, P., Miller, C., Pickernell, D., \& Thomas, B. (2010). Attitudes towards entrepreneurship education: a comparative analysis. Education+ Training, v. 52 , n. 8/9, pp. 568-586.

Padilla-Angulo, L. (2019). Student associations and entrepreneurial intentions. Studies in Higher Education, v. 44, n. 1, pp. 45-58.

Peterman, N. E., \& Kennedy, J. (2003). Enterprise education: Influencing students' perceptions of entrepreneurship. Entrepreneurship Theory and Practice, v. 28, n. 2, pp. 129-144. 
Piperopoulos, P., \& Dimov, D. (2015). Burst bubbles or build steam? Entrepreneurship education, entrepreneurial self-efficacy, and entrepreneurial intentions. Journal of Small Business Management, v. 53, n. 4, pp. 970-985.

Pittaway, L., \& Cope, J. (2007). Simulating entrepreneurial learning: Integrating experiential and collaborative approaches to learning. Management Learning, v. 38, n. 2, pp. 211-233.

Pittaway, L., \& Cope, J. (2007). Entrepreneurship education: a systematic review of the evidence. International Small Business Journal, v. 25, n. 5, pp. 479-510.

Politis, D. (2005). The process of entrepreneurial learning: A conceptual framework. Entrepreneurship Theory and Practice. July. pp. 399-424.

Preedy, S., \& Jones, P. (2015). An investigation into university extra-curricular enterprise support provision. Education+Training, v. 57, n. 8/9, pp. 992-1008.

Rae, D., Gee, S., \& Moon, R. (2010). The role of an entrepreneurial learning team in creating an enterprise culture in a university. In Handbook of Research in Entrepreneurship Education. Edward Elgar Publishing. Massachusetts, USA.

Rasmussen, E. A., \& Sørheim, R. (2006). Action-based entrepreneurship education. Technovation, v. 26, n. 2, pp. 185-194.

Rauch, A., \& Hulsink, W. (2015). Putting entrepreneurship education where the intention to act lies: An investigation into the impact of entrepreneurship education on entrepreneurial behavior. Academy of Management Learning \& Education, v. 14, n. 2, pp. 187-204.

Ribeiro, A. T. V. B., \& Plonski, G. A. (2019). Grassroots Movements: New Gears in the Engine of Brazilian University Entrepreneurship Ecosystems. In Startups and Innovation Ecosystems in Emerging Markets (pp. 179-201). Palgrave Macmillan, Cham. 
Ribeiro, A. T. V. B., Uechi, J. N., \& Plonski, G. A. (2018). Building builders: entrepreneurship education from an ecosystem perspective at MIT. Triple Helix, v. 5, n. 1, pp. 1-20.

Ribeiro, A. T. V. B., Zancul, E. D. S., Axel-Berg, J. H., \& Plonski, G. A. (2018). Can universities play an active role in fostering entrepreneurship in emerging ecosystems? A case study of the University of São Paulo. International Journal of Innovation and Regional Development, v. 8, n. 1, pp. 1-22.

Rideout, E. C., \& Gray, D. O. (2013). Does entrepreneurship education really work? A review and methodological critique of the empirical literature on the effects of university-based entrepreneurship education. Journal of Small Business Management, v. 51, n. 3, pp. 329-351.

Sánchez, J. C. (2011). University training for entrepreneurial competencies: Its impact on intention of venture creation. International Entrepreneurship and Management Journal, 7(2), 239-254.

Sánchez, J. C. (2013). The impact of an entrepreneurship education program on entrepreneurial competencies and intention. Journal of Small Business Management, v. 51, n. 3, pp. 447-465.

Shane, S., \& Venkataraman, S. (2000). The promise of entrepreneurship as a field of research. Academy of Management Review, v. 25, n. 1, pp. 217-226.

Sidhu, I., Singer, K., Suoranta, M., \& Johnsson, C. (2014). Introducing Berkeley Method of Entrepreneurship-a game-based teaching approach. In The 74th annual meeting of the Academy of Management. Philadelphia, Pennsylvania, USA.

Smith, W. K., Gonin, M., \& Besharov, M. L. (2013). Managing social-business tensions: A review and research agenda for social enterprise. Business Ethics Quarterly, v. 23, n. 3, pp. 407-442. 
Souitaris, V., Zerbinati, S., \& Al-Laham, A. (2007). Do entrepreneurship programmes raise entrepreneurial intention of science and engineering students? The effect of learning, inspiration and resources. Journal of Business Venturing, v. 22, n. 4, pp. 566-591.

Taatila, V. P. (2010). Learning entrepreneurship in higher education. Education+ Training, v. 52, n. 1, pp. 48-61.

Uthman, O. A., Okwundu, C. I., Wiysonge, C. S., Young, T., \& Clarke, A. (2013). Citation classics in systematic reviews and meta-analyses: who wrote the top 100 most cited articles?. PloS One, v. 8, n. 10, e78517.

Vesper, K. H. (1982). Research on education for entrepreneurship. Encyclopedia of Entrepreneurship, 321.

Von Graevenitz, G., Harhoff, D., \& Weber, R. (2010). The effects of entrepreneurship education. Journal of Economic Behavior \& Organization, v. 76, n. 1, pp. 90-112.

Wang, C. L., Chugh, H. (2014). Entrepreneurial learning: past research and future challenges. The International Journal of Management Reviews, v. 16, n. 1, pp. 24-61.

Westhead, P., \& Solesvik, M. Z. (2016). Entrepreneurship education and entrepreneurial intention: do female students benefit?. International Small Business Journal, v. 34, n. 8, pp. 979-1003.

Wilson, F., Kickul, J., \& Marlino, D. (2007). Gender, Entrepreneurial Self-Efficacy, and Entrepreneurial Career Intentions: Implications for Entrepreneurship Education. Entrepreneurship Theory and Practice, v. 31, n. 3, pp. 387-406.

Young, J. E. (2000). Entrepreneurship education and learning for university students and practicing entrepreneurs. Entrepreneurship, 215, 238.

Zhang, Y., Duysters, G., \& Cloodt, M. (2014). The role of entrepreneurship education as a predictor of university students' entrepreneurial intention. International Entrepreneurship and Management Journal, v. 10, n. 3, pp. 623-641.

Zhou, L. (2007). The effects of entrepreneurial proclivity and foreign market knowledge on early internationalization. Journal of World Business, v. 42, n. 3, pp. 281-293. 